\title{
Preface: Patterns and processes of meiofauna in freshwater ecosystems
}

\author{
Nabil Majdi $($ J Jenny M. Schmid-Araya $\cdot$ Walter Traunspurger
}

Received: 10 April 2020/Revised: 8 May 2020/Accepted: 14 May 2020/Published online: 26 May 2020

(C) Springer Nature Switzerland AG 2020

\begin{abstract}
Never heard of harpacticoids, ostracods, gastrotrichs or microturbellarians? This is no surprise, they are so tiny! Yet these taxa and many others more famous (nematodes, rotifers, or tardigrades) show complex behaviours and extraordinary physiologies that allow them to colonize inland waters worldwide. This exuberant fauna is better known as the meiofauna (or meiobenthos). Meiofaunal organisms have been fascinating study objects for zoologists since the seventeenth century and recent research has demonstrated their intermediate role in benthic food webs. This special issue highlights how meiofauna can help freshwater ecologists to describe and predict species distribution patterns, to assess production of biomass and trait functions relationships, as well as to examine the trophic links between microscopic and macroscopic worlds and to better understand species' resilience to environmental extremes. Overall, meiofaunal organisms are bridging scales, and as such they
\end{abstract}

Guest editors: Nabil Majdi, Jenny M. Schmid-Araya \& Walter Traunspurger / Patterns and Processes of Meiofauna in Freshwater Ecosystems

N. Majdi $(\bowtie) \cdot$ W. Traunspurger Department of Animal Ecology, Bielefeld University, Bielefeld, Germany

e-mail: nabil.majdi@uni-bielefeld.de

J. M. Schmid-Araya

Department of Life and Environmental Sciences,

Bournemouth University, Poole, UK deserve better integration to develop more comprehensive concepts and theories in ecology.

Keywords Invertebrates - Distribution - Body size · Trophic interactions $\cdot$ Meiobenthos

A lifetime can be spent in a Magellanic voyage around the trunk of a single tree.

-Edward O. Wilson.

And not all of what one might learn from such a voyage would be transferable to the next tree.

-An elegant chaos, Nature Editorial 11 March 2014.

The meiofauna comprises small-sized organisms attached or associated to particles and benthic substrates, commonly depicted as those passing through a $1 \mathrm{~mm}$ and retained on a $42 \mu \mathrm{m}$ mesh net (Fenchel, 1978; Higgins \& Thiel, 1988). Within this size-range, a plethora of phyla is included from microscopic protists and rotifers to almost macroscopic oligochaetes, water mites and chironomids (see Fig. 1 and front cover of the special issue). The most numerically dominant groups in freshwater systems are protists, rotifers, nematodes, oligochaetes, microcrustaceans and larval chironomids, but also tardigrades, gastrotrichs and microturbellarians can achieve high densities in some habitats.

We performed an analysis of the recent meiofaunal literature searching peer-reviewed publications issued 

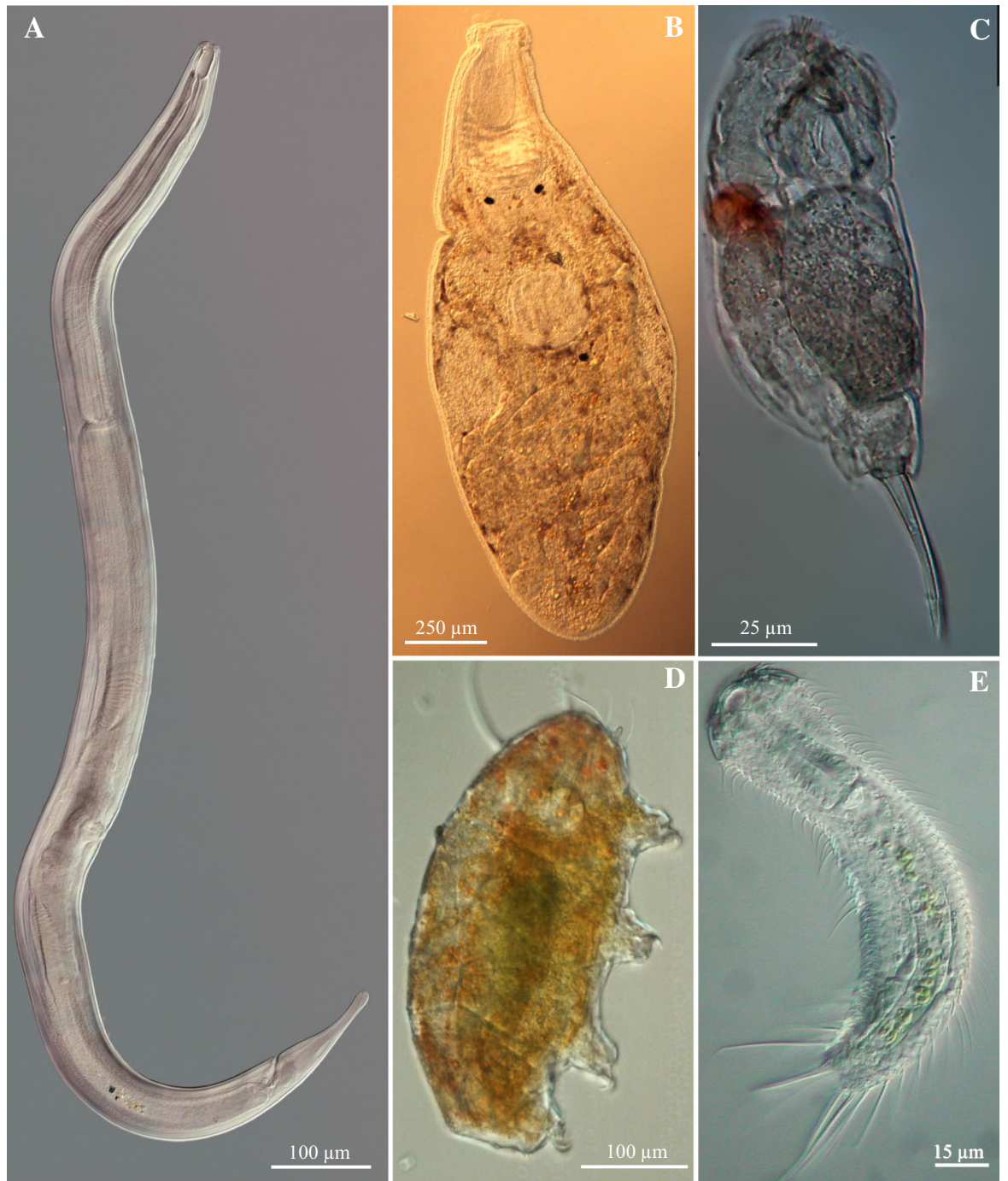

Fig. 1 Some examples of freshwater meiofauna. A Nematode. B Microturbellarian. C Rotifer. D Tardigrade. E Gastrotrich. Source: Photos courtesy of W. Traunspurger, J.P.S. Smith III, P.E. Schmid, N. Majdi and M. Balsamo, respectively

between 2000 and 2018. The listed results were based on searches in Google Scholar and ISI Web of Science databases. A total of 795 titles contained the terms "meiofauna" or "meiobenthos", which we further classified as freshwater or marine studies based on the location of experimental sites, the provenance of organisms or the experimental conditions applied in case studies were performed in the laboratory. From 2000 to 2018 , 174 (i.e. 21.8\%) studies dealt with freshwater while $621(72.2 \%)$ with marine meiofauna (Fig. 2), which highlights the relative paucity of freshwater meiofauna studies in comparison with marine meiofauna studies. We do not aim to speculate about what could cause such a bias, but it might be due to different background and dynamics of limnological and oceanographical research, the number of publications published yearly in oceanography being on average 4 times higher than that in limnology (Downing, 2014). Nevertheless, in his analysis of the literature, Downing (2014) counted about 2000 limnology-related papers published by the year 2000, while 4000 limnology-related papers were published by 2013 ! When comparing with our own literature analysis (Fig. 2), it becomes clear that (1) meiofauna is a fairly marginal research topic within the broader field of limnology $(<1 \%$ of papers published every 
Fig. 2 Yearly number of publications containing the words "meiofauna" OR "meiobenthos" over the period 2000-2018. Studies were distinguished as freshwater or marine

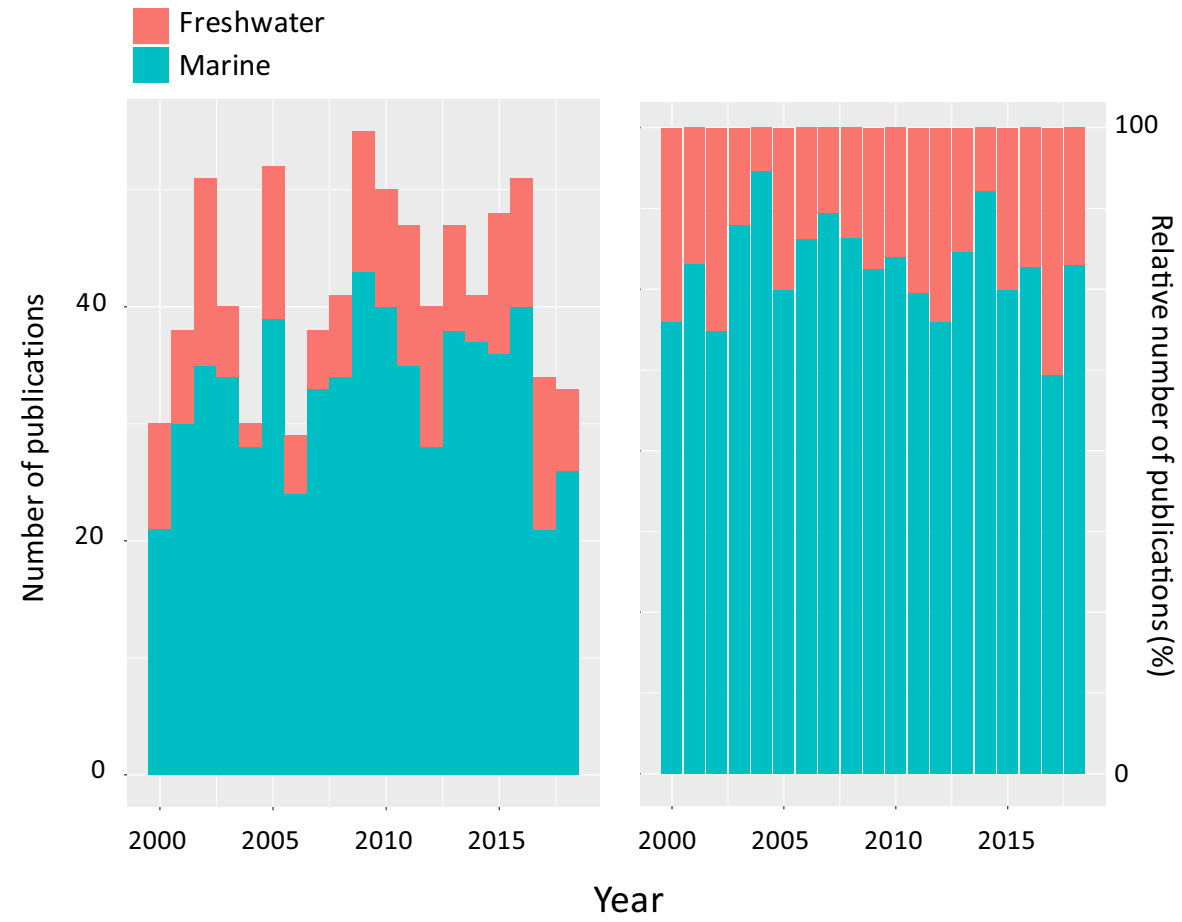

year). And (2) more worryingly, the number of freshwater meiofauna publications do not show any increasing trend through time in contrast with the rapidly growing field of limnology.

The results of a text-mining search examining the semantic field used in publication titles revealed that most studies on freshwater meiofauna mentioned streams and community structure, while marine studies also mentioned distributional aspects with a generally more balanced semantic field giving a relatively larger word-cloud (Table 1, Fig. 3). Analyses and graphical representations were performed under R computational framework ( $\mathrm{R}$ Core Team, 2019) using packages $t m$ (Feinerer \& Hornik, 2019), SnowballC (Bouchet-Valat, 2019) and wordcloud (Fellows, 2018). Also biofilm habitats were more often mentioned in freshwater titles, while in comparison, marine meiobenthologists seemed to focus their studies on sediment-dwelling meiofauna. Obvious is also the preponderance of nematode studies and the lack of investigations on other meiofaunal taxa, particularly, soft-bodied meiofauna in freshwater but also in marine systems (Table 1, Fig. 3). Perhaps this reflects the practical difficulties dealing with taxonomic groups such as the soft-bodied meiofauna (e.g.
Table 1 Top 10 words or word abbreviations used in the titles of publications on "meiofauna" OR "meiobenthos" over the period 2000-2018

\begin{tabular}{lllll}
\hline Freshwater & & & Marine & \\
\cline { 5 - 5 } Word & $\%$ & & Word & $\%$ \\
\hline stream & 3.24 & & distribut & 2.49 \\
communit & 2.92 & & communit & 2.33 \\
biofilm & 1.78 & & sediment & 2.22 \\
nematod & 1.70 & & sea & 2.03 \\
effect & 1.62 & & beach & 1.78 \\
lake & 1.62 & & effect & 1.70 \\
freshwater & 1.46 & & coast & 1.67 \\
river & 1.30 & & sand & 1.62 \\
aquatic & 1.22 & & benthic & 1.51 \\
structure & 1.14 & & nematod & 1.48 \\
\hline
\end{tabular}

Words or word abbreviations are listed by decreasing order of their relative frequency of occurrence in the titles. Words like "meiofauna" OR "meiobenthos" are not regarded, as common English stop words and conjunctions. Words highlighted in bold are shared across both Top 10 lists. The search engine considered words reduced to their word stem, see also expanded word clouds on Fig. 3 


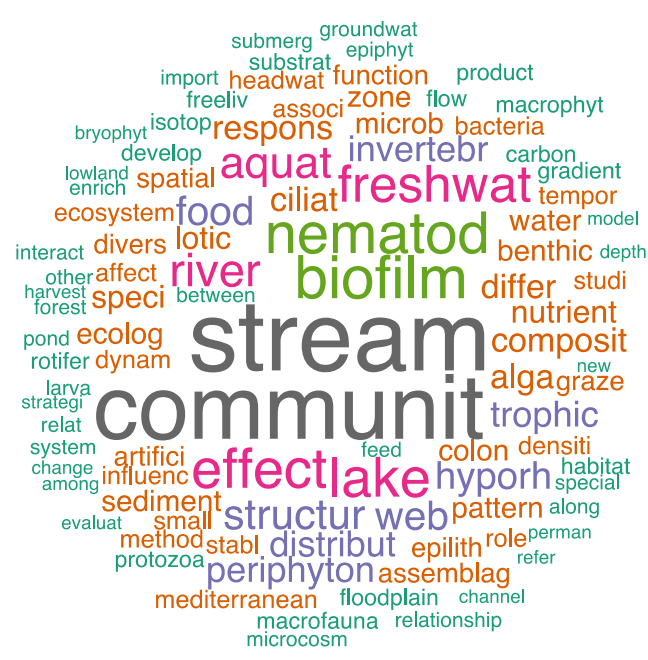

A Freshwater meiofauna

Fig. 3 Word clouds representing the 100 most frequent words contained in the titles of publications also containing the words "meiofauna" OR "meiobenthos" over the period 2000-2018. Word clouds specific to A: freshwater or B: marine studies were distinguished. Different font size and colour show different frequencies of occurrence (the greatest frequencies for dark,

ciliates, rotifers, microturbellarians and gastrotrichs), which have to be assessed live.

Despite the publications of a special issue-mostly about the taxonomy and ecology of stream meiofauna-in the journal Freshwater Biology 20 years ago (Robertson et al., 2000) and a further dedicated book (Rundle et al., 2002), it appears that relatively few studies have considered this group of organisms in freshwater ecosystems since the last two decades (Fig. 2). With this new special issue, we seek to provide an update and an overview of the field of freshwater meiofaunal research, highlighting in which direction this research field has developed since the last two decades (Fig. 3). We also seek to move from the description of lotic meiofaunal communities for the past special issue to a more integrated understanding of the role of meiofauna in different types of freshwater ecosystems. The present special issue named "patterns and processes of meiofauna in freshwater ecosystems" includes 10 publications that provide new insights on the status of freshwater meiofaunal research with the objective to foster the

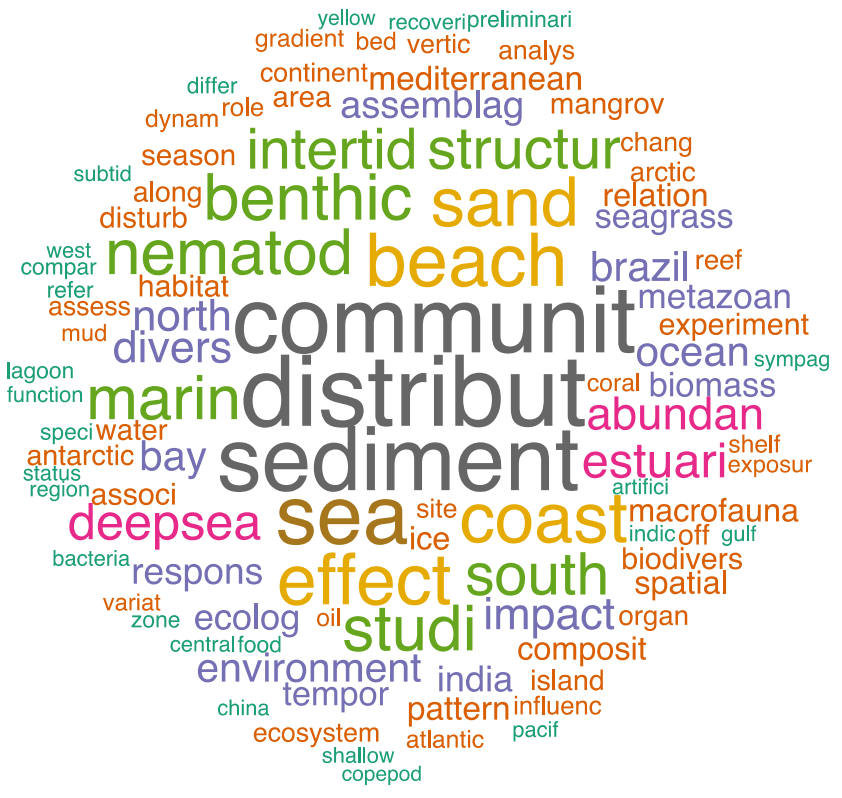

B Marine meiofauna

large font words). The different diameters of word clouds are due to a more even repartition of frequencies in the marine dataset (Table 1). Numbers, punctuations, common English stop words, conjunctions and of course "meiofauna" or "meiobenthos" were removed from the text data. Stemming was used to count stem words only, explaining the lack of suffixes

inclusion of meiofaunal communities in our understanding of freshwater ecosystem functioning. Below, we briefly summarize the aims of the collection of publications against their general background and we point out some interesting avenues of research for future studies.

Many studies have reported a high meiofauna biodiversity in diverse types of habitats, but very few have considered the real contribution of meiofauna to the local biodiversity by integrating all body sizes of benthic metazoans in a particular system. From the few publications that include all metazoans of streams, 58 to $82 \%$ are species belonging to the meiofauna (Robertson et al., 2000; Schmid \& Schmid-Araya, 2000). In the last two decades, molecular approaches have developed considerably with a potential to better help estimating the genuine contribution of meiofaunal diversity. However, such new approaches do have pitfalls and need careful choices, calibrations and interpretations (Tang et al., 2012; Leasi et al., 2018) while some few publications dealing with freshwater systems have revealed that genetic procedures cannot 
yet resolve, for instance, soft-bodied meiofauna to species and genus level (Weigand \& Macher, 2018). In this special issue, Schenk \& Fontaneto (2020) deliver a timely review of the most recent advances in DNA sequence data used for improving the status of meiofaunal biodiversity. They argue that meiofauna diversity is affected by at least two knowledge shortfalls depicted by Hortal et al. (2015): the Linnean (lack of species description) and the Wallacean (lack of species geographic distribution knowledge). They discuss an array of genetic techniques and associated bioinformatics, highlighting the pros and cons of each technique thus providing a roadmap for future studies. Using the appropriate tools and good practices, one has the opportunity to include meiofaunal diversity in large-scale monitoring studies.

To this date, the identification of species and the composition of meiofaunal assemblages are biased to the Holarctic zone even when it is known that ecosystems at lower latitudes are generally more diverse. The only meiofaunal group that has been relatively well assessed in different biogeographic zones are nematodes, and, consequently, enabling some preliminary conclusions about their global distribution (e.g. Eyualem-Abebe \& Ley, 2008; Van Den Hoogen et al., 2019). For all other freshwater meiofaunal groups we have a very limited knowledge about their true diversity and biogeography worldwide. Here, Balsamo et al. (2020) highlight the diversity, biogeographic distribution patterns and ecology of the Rouphozoa, a very neglected clade of soft-bodied animals that are represented here by gastrotrichs and microturbellarians. They provide "Rouphozoa-friendly" methods of sampling, extraction of individuals from field samples, and DNA barcoding. In their review, they also unravel their remarkable life- and feeding strategies, concluding with an overview of the global distribution of the species known to science. They propose avenues for future investigations based on evolutionary mechanisms (e.g. genome duplication or reduction, reproduction traits related to sexual selection) and on interesting ecological aspects (e.g. feeding-type distinctions, niche differentiation, dispersal abilities).

Studies in both marine and freshwater have given great attention to community ecology and species distributions over the last two decades (Fig. 3). Indeed, meiofaunal species have short population turnover rates and, therefore, their community structure could hypothetically quickly respond to environmental constraints, making these assemblages ideal models for ecological concepts and ecosystem theory. In nature, communities do not exist in isolation and the way each community is affected by diverse dispersal mechanisms has been the rationale behind the concept of "metacommunities" reviewed here by Gansfort et al. (2020) in terms of freshwater meiofaunal assemblages. However, from their review it is evident that most metacommunity studies are restricted to ostracods, rotifers and nematodes. They conclude that these groups differ in their dispersal abilities and in their responses to the type of habitat. Thus, at least for these groups, and particularly for ostracods, mechanisms of species sorting and its interaction with dispersal limitations at different spatial scales appear to be the main structuring force in these assemblages. However, further studies need to consider a wider range of taxa and freshwater habitats to test thoroughly any predictions of metacommunity concepts jointly in micro-, meio- and macrofaunal communities.

Because meiofauna are ubiquitous, easy and cheap to sample, to store, to work with (though one might believe that they are impossible to identify and tedious to manipulate-which is definitely not true); Because they are intimately associated with substrates; Because they have high turnover rates and all-benthic life cycles; Because they quickly respond to environmental alterations. For all these reasons meiofauna are wonderful bio-indicators of pollution or disturbances that are unfortunately not yet been used at their full potential. Lake eutrophication is a large threat worldwide caused by human activities, and Traunspurger et al. (2020) emphasize in their review the potential of meiofauna to assess the trophic status of lentic systems. They investigate the abundance, biomass and species richness of some meiofaunal taxa and their relationship with the trophic state of lakes, substrate types (hard versus soft bottom) and water depth (littoral versus profundal). They show that meiofauna is more abundant in the biofilm covering hard substrates in littoral zones. Further, meiofauna biomass tends to be higher in eutrophic lakes as a result of a greater number of copepods dwelling hard-substrates, and of greater numbers of oligochaetes and nematodes in soft substrates. To assess responses of community structure and food webs, nematode assemblages were further examined and showed marked 
variations in diversity, which was influenced by lake trophy. A comparison of feeding traits of nematodes revealed that in the lake profundal, species-poor nematode assemblages are characterized by a very high proportion of large, omnivorous or predatory nematodes, suggesting singular nematode-dominated trophic channels in the profundal zone of lakes.

In the last 20 years, benthic studies in lakes and streams have estimated production and biomass ranging from bacteria to macrofauna. However, not a single production method allows direct comparisons between micro-, meio- and macrofaunal groups. Here, Schmid-Araya et al. (2020) stress that although a plethora of methods has been used to estimate meiofaunal production, only a handful of studies have compared the biomass production of meio- and macrozoobenthic organisms. They highlight in their review that the meiofauna can substantially contribute to metazoan production. Despite the variety of methods used, the production of benthic protists as well as all major meiofauna taxa can be well predicted by system-specific allometric relations proposed in the current study. Schmid-Araya et al. (2020) suggest that this tentative model based on temperature-adjusted production and biomass of meiofaunal species from lakes, wetlands, and streams, should be further assessed through additional data from future biomass production studies.

Aquatic studies usually use the size spectrum of individuals to characterize scaling relations in communities, displaying total abundance or biomass in logarithmical intervals of body size. In contrast, Schmid et al. (2020) argue that although biomass represents a link between different trophic levels and size scaling within ecosystems, no study has assessed the species-specific biomass distribution at assemblage- and community-level and their biomass variation within and among ecosystems. They assessed the body size and biomass distribution and their variance of local and regional species assemblages (including more than 1200 benthic protists, meio- and macroinvertebrate species) in seven geographically separated river catchments, using stochastic assemblage models. Their results stress that the observed species composition and biomass variations of those communities display a fractal fluctuation scaling, independent of trophic level, governed by the frequency of systemspecific peak flow events.
Critical to an overall understanding of community structure and functioning of ecosystems is also the fact that only few studies incorporated the naturally cooccurring unicellular together with the wide sizerange of invertebrates. Due to the disparate number of phyla that defines the freshwater meiofauna and their benthic lifestyle, benthic communities are characterized by an enormous diversity of morphologies, behavioural patterns, life history traits and functional feeding traits. In this special issue, Neury-Ormanni et al. (2020) examine the seasonal shift in a biofilmdwelling community composed namely of micro- and meiofauna. They propose a new database of morphofunctional traits, which they use to characterise seasonal responses and shifts in feeding behaviour and the preponderance of feeding types ranging from filter feeders preying on small-sized organism in winter to diversified feeding modes that include a wide spectrum of food sources in spring. Therefore, even at small scales ranging between $2 \mu \mathrm{m}$ to $2 \mathrm{~mm}$, complex feeding patterns and responses define these biofilmdwelling assemblages.

Freshwater meiofauna are nearly invisible to the eye and live in a hidden benthic world made of sand grains, interstitial pores, biofilms and detrital particles. It is therefore no surprise that little is known about their diet and feeding strategies. However, there is compelling evidence about the close relationship between meiofaunal biomass and the biomass of the microphytobenthos (i.e. micro-algae and cyanobacteria; Peters \& Traunspurger, 2005; Bogut et al., 2009; Majdi et al., 2012; Schroeder et al., 2012), suggesting that the meiofauna community play a complex and important role in benthic food webs (see also SchmidAraya et al., 2016). Here, Majdi et al. (2020) provide an overview of this field of research highlighting a wide range of methodologies used to unravel meiofaunal diets, ranging from gut content analyses to measures of assimilation using trophic biomarkers such as stable isotopes or fatty acids. Many of the above methodologies need a substantial number of meiofaunal individuals to meet the requirement of these analytical tools. However, Majdi et al. (2020) are hopeful that these procedures as well as new techniques in microscopy and spectroscopy can be adapted to the size of the meiofauna to quantitatively assess their feeding and, thus, understand their contribution to ecosystem fluxes of energy and matter. 
The meiofauna occupies various trophic levels irrespective of their size spectrum whereby species can seasonally switch their diet thereby shifting between trophic levels (Schmid-Araya et al., 2016; Majdi \& Traunspurger, 2017; Weitere et al., 2018; Neury-Ormanni et al., 2020). Thus, this group is essential to understand the trophic dynamics of any benthic freshwater system. There is clearly an avenue of research regarding the role of meiofauna in the carbon and nitrogen cycle, with their ability to locally influence the activities of heterotrophs, methanotrophs and nitrifiers. In this special issue, Ptatscheck et al. (2020) examine whether meiofaunal organisms represent a significant diet for a variety of freshwater benthic macroinvertebrates but also for young fish species. They explain that although gut analyses of macrofauna and fish reveals a wide spectrum of meiofaunal prey species, studies on ingestion rates are rarer. The few laboratory experiments on predatorprey relations (functional responses) have shown a high consumption of meiofaunal prey (mostly nematodes) by diverse predatory and/or non-predatory species. They also examine the role of substrate complexity because labyrinthine sediment pore interfaces provide refugia from predation (Schmid, 1999). Thus, they conclude that future research needs to account for prey-choice as all functional response experiments have been conducted with single prey species (mostly nematodes) and not with a wide range of meiofaunal groups or species.

Among meiofaunal taxa, tardigrades, rotifers and nematodes show outstanding capabilities to withstand extreme environmental fluctuations. Many of those species thrive-well in harsh aquatic environments, such as intermittent streams, temporary ponds, glacier streams, hot springs, but also in mosses and lichens. Here, Rebecchi et al. (2020) compare the various adaptations found in tardigrades, nematodes and rotifers and reviewed the mechanisms they used to cope with desiccation, extreme temperatures and radiations. Because of their unique ability to resist harsh conditions, tardigrades and rotifers have been proposed as model organisms in the fields of exobiology and medical research. Highlighting the ecological and evolutionary consequences of extreme tolerance to a spectrum of climatic conditions, it is possible to predict the biogeographic distribution and, therefore, the ecological success of these organisms in a changing environment.
Overall the studies from this special issue stress that the role of freshwater meiofauna within the functioning of freshwater ecosystems has yet to be more firmly established, while previous studies in marine systems established their role in carbon mineralisation, and within the detrital trophic pathways. In freshwaters, we have obtained data on these trophic pathways only for some nematodes species (Traunspurger et al., 1997; Mathieu et al., 2007), but we now need to move forward and integrate all other micro-meiofauna taxa showing a diversity of lifestyles and feeding strategies, and presumably playing leading roles in freshwater ecosystems. There are still many more questions that we have not yet answered, but by now, we need to reflect why there are no more ecological studies incorporating a wider range of sizes that might include the micro-, meio- and macrofauna? It has to be pointed out, that for instance, production studies excluding small-sized organisms fundamentally underestimate the overall budget of an ecosystem. The ubiquitousness of the meiofauna means that they will always be there and perhaps this is the unique characteristic, and no matter where one looks one will always find it.

Acknowledgements The idea of this special issue was first born at the 16th International Meiofauna Conference held in Heraklion (Greece) in 2016. We would like to thank the International Association of Meiobenthologists creating opportunities for meeting and discussing such collaborative projects. We warmly thank our colleagues that have responded positively to our invitation and have made this special issue possible. We are grateful to Diego Fontaneto and Sidinei M. Thomaz for their help and kind support at all the stages of the editing process. We acknowledge the serious work of all anonymous referees who gave constructive criticisms and help us to improve the manuscripts. We thank Peter E. Schmid for his help preparing this preface. Finally, in the difficult times we all face in this year of the pandemic of SARS-CoV-2, we want to express all our support and solidarity for our colleagues, health and social care specialists.

\section{References}

Balsamo, M., T. Artois, J. P. S. Smith III, M. A. Todaro, L. Guidi, B. S. Leander \& N. W. L. Van Steenkiste, 2020. The curious and neglected soft-bodied meiofauna: Rouphozoa (Gastrotricha and Platyhelminthes). Hydrobiologia. https:// doi.org/10.1007/s10750-020-04287-x.

Bogut, I., J. Vidakovic, D. Cerba \& G. Palijan, 2009. Epiphytic meiofauna in stands of different submerged macrophytes. Ekoloji 70: 1-9.

Bouchet-Valat, M., 2019. SnowballC: Snowball Stemmers Based on the C 'libstemmer' UTF-8 Library. R package 
version 0.6.0. https://CRAN.R-project.org/package= SnowballC.

Downing, J. A., 2014. Limnology and oceanography: two estranged twins reuniting by global change. Inland Waters 4: 215-232.

Eyualem-Abebe, W. Decraemer \& P. De Ley, 2008. Global diversity of nematodes (Nematoda) in freshwater. Hydrobiologia 595: 67-78.

Feinerer, I. \& K. Hornik, 2019. tm: Text Mining Package. R package version 0.7-7. https://CRAN.R-project.org/ package $=\mathrm{tm}$.

Fellows, I., 2018. wordcloud: Word Clouds. R package version 2.6. https://CRAN.R-project.org/package=wordcloud.

Fenchel, T. M., 1978. The Ecology of Micro-and Meiobenthos. Annual review of Ecology and Systematics 9: 99-121.

Gansfort, B., D. Fontaneto \& M. Zhai, 2020. Meiofauna as a model to test paradigms of ecological metacommunity theory. Hydrobiologia. https://doi.org/10.1007/s10750020-04185-2.

Higgins, R. P. \& H. Thiel, 1988. Introduction to the Study of Meiofauna. Smithsonian Institution Press, Washington, DC.

Hortal, J., F. de Bello, J.A.F. Diniz-Filho, T.M. Lewinsohn, J.M. Lobo \& R.J. Ladle, 2015. Seven shortfalls that beset largescale knowledge of biodiversity. Annual Review of Ecology, Evolution, and Systematics 46: 523-549.

Leasi, F., J.L. Sevigny, E.M. Laflamme, T. Artois, M. CuriniGalletti, A. de Jesus Navarrete, M. Di Domenico, F. Goetz, J. A. Hall et al., 2018. Biodiversity estimates and ecological interpretations of meiofaunal communities are biased by the taxonomic approach. Communications Biology 1: 112.

Majdi, N. \& W. Traunspurger, 2017. Leaf fall affects the isotopic niches of meiofauna and macrofauna in a stream food web. Food Webs 10: 5-14.

Majdi, N., M. Tackx, J. Leflaive, S. Boulêtreau, L. Ten-Hage, F. Julien, R. Fernandez \& E. Buffan-Dubau, 2012. The relationship between epilithic biofilm stability and its associated meiofauna under two patterns of flood disturbance. Freshwater Science 31: 38-50.

Majdi, N., J. M. Schmid-Araya \& W. Traunspurger, 2020. Examining the diet of meiofauna: a critical review of methodologies. Hydrobiologia. https://doi.org/10.1007/ s10750-019-04150-8.

Mathieu, M., J. Leflaive, L. Ten-Hage \& R. D. Wit, 2007. Freeliving nematodes affect oxygen turnover of artificial diatom biofilms. Aquatic Microbial Ecology 49: 281-291.

Neury-Ormanni, J., J. Vedrenne, M. Wagner, G. Jan \& S. Morin, 2020. Micro-meiofauna morphofunctional traits linked to trophic activity. Hydrobiologia. https://doi.org/10.1007/ s10750-019-04120-0.

Peters, L. \& W. Traunspurger, 2005. Species distribution of free-living nematodes and other meiofauna in littoral periphyton communities of lakes. Nematology 7: 267-280.

Ptatscheck, C., H. Brüchner-Hüttemann, B. Kreuzinger-Janik, S. Weber \& W. Traunspurger, 2020. Are meiofauna a standard meal for macroinvertebrates and juvenile fish?. Hydrobiologia. https://doi.org/10.1007/s10750-02004189-y.
R Core Team, 2019. R: A Language and Environment for Statistical Computing. R Foundation for Statistical Computing, Vienna, Austria. https://www.R-project.org/.

Rebecchi, L., C. Boschetti \& D. R. Nelson, 2020. Extremetolerance in meiofaunal organisms: a case study with tardigrades, rotifers and nematodes. Hydrobiologia. https:// doi.org/10.1007/s10750-019-04144-6.

Robertson, A. L., S. D. Rundle \& J. M. Schmid-Araya, 2000. An introduction to a special issue on lotic meiofauna. Freshwater Biology 44: 1-3.

Rundle, S. D., A. L. Robertson \& J. M. Schmid-Araya, 2002. Freshwater Meiofauna. Backhuys Publishers, Leiden.

Schenk, J. \& D. Fontaneto, 2020. Biodiversity analyses in freshwater meiofauna through DNA sequence data. Hydrobiologia. https://doi.org/10.1007/s10750-01904067-2.

Schmid, P. E., 1999. Fractal properties of habitat and patch structure in benthic ecosystems Advances in Ecological Research 30: 339-401.

Schmid, P. E. \& J. M. Schmid-Araya, 2000. Invertebrate assemblages of low-order British and Austrian streams. Jahresbericht der Biologischen Station Lunz 16: 51-72.

Schmid, P. E., J. M. Schmid-Araya \& M. Tokeshi, 2020. The scaling of biomass variance across trophic levels in stream species communities: a macroecological approach. Hydrobiologia. https://doi.org/10.1007/s10750-02004239-5.

Schmid-Araya, J. M., P. E. Schmid, N. Majdi \& W. Traunspurger, 2020. Biomass and production of freshwater meiofauna: A review and a new allometric model. Hydrobiologia. https://doi.org/10.1007/s10750-02004261-7.

Schmid-Araya, J. M., P. E. Schmid, S. P. Tod \& G. F. Esteban, 2016. Trophic positioning of meiofauna revealed by stable isotopes and food-web analyses. Ecology 97: 3099-3109.

Schroeder, F., W. Traunspurger, K. Pettersson \& L. Peters, 2012. Temporal changes in periphytic meiofauna in lakes of different trophic states. Journal of Limnology 71: 216-227.

Tang, C. Q., F. Leasi, U. Obertegger, A. Kieneke, T. G. Barraclough \& D. Fontaneto, 2012. The widely used small subunit $18 \mathrm{~S}$ rDNA molecule greatly underestimates true diversity in biodiversity surveys of the meiofauna. Proceedings of the National Academy of Sciences of the United States of America 109: 16208-16212.

Traunspurger, W., M. Bergtold \& W. Goedkoop, 1997. The effects of nematodes on bacterial activity and abundance in a freshwater sediment. Oecologia 112: 118-122.

Traunspurger, W., B. Wilden \& N. Majdi, 2020. An overview of meiofaunal and nematode distribution patterns in lake ecosystems differing in their trophic state. Hydrobiologia. https://doi.org/10.1007/s10750-019-04092-1.

Van Den Hoogen, J., S. Geisen, D. Routh, H. Ferris, W. Traunspurger, D. A. Wardle, R. G. De Goede, B. J. Adams, W. Ahmad et al., 2019. Soil nematode abundance and functional group composition at a global scale. Nature 572: 194-198.

Weigand, A. M. \& J. N. Macher, 2018. A DNA metabarcoding protocol for hyporheic freshwater meiofauna: Evaluating 
highly degenerate COI primers and replication strategy. Metabarcoding and Metagenomics 2: e26869.

Weitere, M., M. Erken, N. Majdi, H. Arndt, H. Norf, M. Reinshagen, W. Traunspurger, A. Walterscheid \& J. K. Wey, 2018. The food web perspective on aquatic biofilms. Ecological Monographs 88: 543-559.
Publisher's Note Springer Nature remains neutral with regard to jurisdictional claims in published maps and institutional affiliations. 